\title{
IF WE ARE QUIET, WILL THINGS CRY OUT?
}

\section{Mats Burström}

As I read Bjørnar Olsen's retrospect of theoretical trends within Scandinavian archaeology and his prediction for the future development, two associations spontaneously spring to mind. By coincidence, both references are of religious character. The first one is an old Zen Buddhist word of wisdom that goes:

When I was young and knew nothing, a tree was simply a tree, a mountain simply a mountain, and a lake simply a lake. When I had studied and learned some, a tree was much more than a tree, a mountain much more than a mountain, and a lake much more than a lake. When I became enlightened, a tree was once again just a tree, a mountain just a mountain, and a lake just a lake.

The second comes from the Bible (Luke 19:40), where Jesus replies to a demand that he should rebuke his disciples (who had blessed him as a king, coming in the name of the Lord). This quote reads:

I tell you, he replied, if they are quiet, the stones will cry out.

These two references are my starting point for some reflections about the revolutionary character of the future that Olsen predicts for archaeology, as well as about some possibilities and possible difficulties associated with it. 


\section{LEVELS OF UNDERSTANDING}

According to Olsen we may now be witnessing a development towards a new archaeology where archaeology is - just archaeology! Archaeology is no more to be considered as anthropology, or to be primarily concerned with a linguistic or textual understanding of the material record. Nor should we continue our quest for History and Society. Olsen describes this development as possibly representing the unthinkable, that: "a new revolution is underway; more silent perhaps, but also more radical and different than the previous ones".

The core in Olsen's revolutionary new archaeology is an urge to see things as just things, to avoid (over)interpretation, and to accept that, for example, a boat is a boat is a boat (although we are also supposed to recognize all the connotations that follow from the boat's basic function). Olsen's claim should not be understood as a reduction of the importance of things, quite the contrary. By stressing that things have the right to an existence in their own right, not just as things representing something else, Olsen challenges our ability to think beyond the framework of Modernity.

So, according to Olsen we may now be at a turning point where we have learned the lessons from previous theoretical movements and thus are ready to meet things on new and equal terms. He argues that this should not be understood as just another theoretical turn but as an insight that concerns and has consequences for all of archaeology. Recognizing the fundamental importance that the direct encounter with the material past has for our archaeological understanding also makes the delimiting of a specific "theoretical" archaeology less relevant. What Olsen suggests is not a return to an empirical archaeology most concerned with the archaeological record and with less or no concern for its theoretical foundations. I believe, however, that there may be a pedagogical problem here, and that is what brings the words of the Zen Buddhist referred to above to mind.

There is a delusive similarity between the initial and the final level of understanding in the wisdom; to the uninitiated they may indeed appear identical. In both cases a tree, a mountain and a lake are seen as just a tree, a mountain, and a lake (or a thing just as a thing). What separates the different levels of understanding is the intellectual process that has been taking place between the first and last step; a process necessary to reach the deeper insight at the higher level of understanding.

For the theoretically uninterested and therefore uninitiated archaeologist who never jumped on the postprocessual (perhaps not even the processual) bandwagon, Olsen's new archaeology runs the risk of being mistaken for a longed-for return to "real" archaeology; that is, to a straightforward 
empirical archaeology that does not bother with anything else than the archaeological record and with what that record supposedly "tells us". This would be to confuse the first and the last levels of understanding referred to by the Zen Buddhist. There is, of course, a vast difference between the theoretically uninitiated wish for a return to a "real" archaeology and the theoretically well-founded new archaeology advocated by Olsen, but some arguments in the latter may be kidnapped and (mis)used as arguments in favour of the former, i.e. for an old-fashioned empirical archaeology.

Applied to archaeology, the Zen Buddhist wisdom implies a sort of cumulative effect in the theoretical debate. Even though it may be more exciting to focus on revolutions and shifts of paradigms, we should acknowledge that were it not for the explorations done within preceding theoretical frameworks, we would not have discovered their weaknesses and thereby been enabled to formulate new lines of argument and investigation. On this ground I would argue, in contrast to Olsen, that the new archaeology we now see emerging is in fact a kind of continuation and development of postprocessual archaeology, just as the latter is a "natural" successor of processual archaeology. Every new step in the intellectual process is to some extent dependent on the previous ones, even when the new ideas explicitly contradict the old ones.

\section{GIVING THINGS THEMSELVES A SAY}

Bjørnar Olsen wants us do liberate things from the interpretative burdens we as archaeologists have laid upon them; he wants the things themselves to have a say. Things should also have the right to remain things (well, probably also the right to remain silent, I suppose). This is presumably the greatest challenge brought forward by the suggested new archaeology: how are we to give things themselves a say, and how will we be able to understand things on their own terms? The old phrase "It is like talking to a brick wall" gives us a somewhat pessimistic view of the prospects of letting things themselves have a say.

Language is essential for our understanding of the world we live in; language both enables and restricts our knowledge. Language is also essential for our communication; within the humanities language is actually such a crucial part of interpretation that the two are hardly separable. But what language(s) do things themselves speak? And how are we to hear what they say? These fundamental issues brought that biblical quotation to my mind; will things really cry out if we - the archaeologists - are quiet?

Within the proposed new archaeology we are also supposed to oppose the anthropomorphized understanding of things that dominates 
current archaeology; Olsen requests us to stop the "humanizing and interpretative exploitation" of things. The question is, however, whether it is possible to formulate an understanding of things that reaches beyond our human experience of the world and our language. The difficulties of this task are clearly evidenced, as Olsen himself comments upon, by his own use of anthropomorphized metaphors in his final conclusions.

I believe, however, that Bjørnar Olsen is on to something important in stating that, in our quest for understanding things as things, we should be prepared for the possibility that they may "behave in ways banal, trivial or downright boring”. You may, of course, ask how intellectually stimulating this realization is, but it indeed represents an alternative to what Olsen describes as "our current obsession with turning mute things into storytellers or otherwise loading them with interpretative burdens".

In order to explore what things may be able to mediate if we approach them as just things, we need to look outside the conventional academic rules of archaeological writing or thinking. I agree with Olsen's call for a higher degree of trust in the archaeological project and its potential, but I also believe that we may find some inspiration outside our own discipline. One example of a congenial expression of an imagined nonhuman testimony of a material existence is the poem "Grey Rock Song" (Sw. Gråbergssaing) by the Swedish poet Gustaf Fröding (I860-I9II). The poem is one of Fröding's "subhuman songs" where he tries to imagine how trees, animals and other "things" would express themselves in carefully managed words. "Grey rock" is the popular name for the most common kind of bedrock, indeed such a natural element in the everyday Scandinavian life-world that we hardly notice its existence and even more seldom listen to what it may have to say. In the poem, Fröding uses a most decorticated idiom in order to express the essence of a non-human existence. The "subhuman song" reads (translation by Martin Allwood):

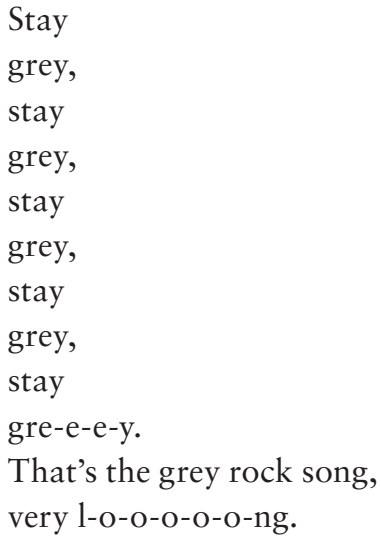


In the coming years I believe there is good reason to reconsider not only our way of thinking about things, but also the way in which we express ourselves as archaeologists, including our use of images. An enlightened archaeology, where things are allowed to be just things, may demand different modes of expression than the ones we presently associate with a theoretically well-founded archaeology. I look forward to this development with curiosity and confidence; let us have an open mind and strive to give things themselves a say.

Mats Burström Department of Archaeology and Classical Studies Stockholm University I06 9I Stockholm

Sweden

\section{REFERENCES}

Fröding, G. [1993]. The Selected Poems of Gustaf Fröding. Translated into English by Henrik Aspán in collaboration with Martin Allwood. Eagleye Books International: Walnut Creek. 